\title{
ショ糖脂肪酸エステルのジゴキシン坐薬基剂への添加と持続作用*1
}

\author{
米沢健三, 山口 勇, 斉藤邦人 ${ }^{* 2 a}$, 金久保好男 ${ }^{* 2 a^{\prime}}$, 中村 護 ${ }^{* 2 b}$ \\ 東北大学医学部附属病院薬郕部*2a \\ 東北大学医学部放射線医学教室*2b
}

\section{Addition of Sugar Fatty Acid Esters to Digoxin Suppository and Its Prolonged Action*1}

\author{
KENZO YONEZAWA, ISAMU YAMAGUCHI, KUNIHITO SAITO*2a \\ YOSHIO KANAKUBO*2'a, and MAMORU NAKAMURA*2b \\ Hospital Pharmacy, Tohoku University*2a \\ Department of Radiology, Tohoku University School of Medicine*2b
}

(Received February 9, 1981)

\begin{abstract}
Rectal suppositories of digoxin were prepared from cacao butter containing $5 \%$ of polysorbate 60 and 1,2 , or $5 \%$ of sucrose fatty acid esters with HLB value of approximately 11 and 15 (SFAE-11, SFAE-15). Physical properties such as melting point, dissolution time and hardness of these suppositories were determind. Blood samples of rabbits were collected at $0.5,1.5,3.0,4.5,7.0$ and 9.0 hours after rectal administration of digoxin $(0.3 \mathrm{mg} /$ $\mathrm{kg}$ ). The plasma digoxin levels were determined by a radioimmunoassay method. Long lasting effect for digoxin suppositories containing SFAE-11 and SFAE-15 was estimated from the relative areas under the concentration-time curve over 0 to 9 hours, and the ratios between 0.5 hour value and 1.5 hour value of plasma digoxin concentration-time curve for digoxin suppositories containing 1,2 , or $5 \%$ of SFAE- 15 were $1.52,2.14$ and 2.23 , respectively. The ratios for the suppositories containing 1,2 , or $5 \%$ of SFAE-11, as determined by Formula 1 as standard, were $0.67,0.87$, and 1.23 , respectively. The ratios between 0.5 hour value for Formula 1 to 7 was $0.55,0.54,0.70,0.89,0.77,0.91$, and 0.94 , respectively.
\end{abstract}

持続性製剤に関する研究はこれまで数多くなされてい るが,これらの研究のなかでショ糖脂肪酸エステル（以 下 SFAEと略す）の作用持続性製剤への応用が掛見 (1) および竹中ら 2$)$ とり，サルファ剤の経口投与で報告さ れている.著者らは先に持続化を目的としてミッロウを ジゴキシン坐剤に添加したが，期待した効果は得られな かっだ)、SFAE は食品添加物に指定されて扣り，医薬

*1 本報を「放射性医莱品の生物薬剂学への応用」第 4 報とする．本報の一部 は第18回日本薬学会東北 支部大会 (仙台, 1979年10月) で発表.

*2a,2b 仙台市星陵町 1-1; 1-1, Seiryo-cho, Sendaishi, 980 Japan

*2a' 現所属: 千葉大学医学部附属病院薬䠼部
用としてシロップ剂, 滑沢剂, 崩壊剤などに使用されて いる4).SFAE の坐剂に拈ける持続作用を研究する目的 で，カカオ脂に添加した基剤でジジキシン坐剤を調製 し, ジゴキシン血中動態を polysorbate 60 添加カカオ 脂基剤で調製したジジシン坐剤を基準坐剂として比較 検討した.

\section{实 网 部}

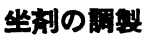

SFAE (第一工業製薬製, 食品添加物) は, HLB 約 11 (以下 SFAE-11とする) および 15 (以下 SFAE-15 と する） 2 種類を選んた。. 100meshで穊過したジゴキシ ン（E・MERCK 製）をガラス乳鉢に入れ，次に SFAE 
を少量ずつ混合しながら加光これに $60^{\circ}$ 以下で愹融し たカカオ脂（保栄薬工製）を少量ずつ混合しながら全量 加える.これを磁製皿に移し，よく摫拌しながらERWE $\mathrm{KA}$ 製坐剤用鋳型に注入し 成形した．基準坐剂として使 用した $5 \%$ polysorbate 60 添加ジゴシン坐剂（以下 I とする) は，熔融したカカオ脂に polysorbate 60 を
少量ずつ加え混合し，これをガラス乳錸中のジゴキシン 末に少量ずつよく混合しながら全量とし，以下SFAE添 加坐剤と同様に調製した. 坐剂は魚雷型で長さ $2.6 \mathrm{~cm}$, 底部直径 $7 \mathrm{~mm}$, 最大直径 $8.5 \mathrm{~mm}$, 重量約 $1 \mathrm{~g}, 1 \mathrm{~g}$ 中の

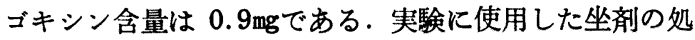
方を Table 1 に示す.

Table 1. Formula of Suppositories

\begin{tabular}{|c|c|c|c|c|c|}
\hline No. & Ingredient & Quantity & . No. & Ingredient & Quantity \\
\hline 1 & $\begin{array}{l}\text { Digoxin } \\
\text { Polysorbate } 60 \\
\text { Cacao butter ad }\end{array}$ & $\begin{array}{l}180 \mathrm{mg} \\
10 \mathrm{~g} \\
200 \mathrm{~g}\end{array}$ & 5 & $\begin{array}{l}\text { Digoxin } \\
\text { SFAE-15**} \\
\text { Cacao butter ad }\end{array}$ & $\begin{array}{c}180 \mathrm{mg} \\
2 \mathrm{~g} \\
200 \mathrm{~g}\end{array}$ \\
\hline 2 & $\begin{array}{l}\text { Digoxin } \\
\text { SFAE } 11^{*} \\
\text { Cacao butter ad }\end{array}$ & $\begin{array}{c}180 \mathrm{mg} \\
2 \mathrm{~g} \\
200 \mathrm{~g}\end{array}$ & 6 & $\begin{array}{l}\text { Digoxin } \\
\text { SFAE-15 } \\
\text { Cacao butter ad }\end{array}$ & $\begin{array}{c}180 \mathrm{mg} \\
4 \mathrm{~g} \\
200 \mathrm{~g}\end{array}$ \\
\hline 3 & $\begin{array}{l}\text { Digoxin } \\
\text { SFAE-11 } \\
\text { Cacao butter ad }\end{array}$ & $\begin{array}{c}180 \mathrm{mg} \\
4 \mathrm{~g} \\
200 \mathrm{~g}\end{array}$ & 7 & $\begin{array}{l}\text { Digoxin } \\
\text { SFAE- } 15 \\
\text { Cacao butter ad }\end{array}$ & $\begin{array}{l}180 \mathrm{mg} \\
10 \mathrm{~g} \\
200 \mathrm{~g}\end{array}$ \\
\hline 4 & $\begin{array}{l}\text { Digoxin } \\
\text { SFAE-11 } \\
\text { Cacao butter ad }\end{array}$ & $\begin{array}{c}180 \mathrm{mg} \\
10 \mathrm{~g} \\
200 \mathrm{~g}\end{array}$ & & & \\
\hline & $\begin{array}{r}\text { *: Sucrose fatty } \\
\text { approximately } \\
\text { **: Sucrose fatty } \\
\text { approximately }\end{array}$ & $\begin{array}{l}\text { acid es } \\
11 \\
\text { acid es } \\
15\end{array}$ & $r$ & $\begin{array}{l}\text { th } H L B \text { value of } \\
\text { th } H L B \text { value of }\end{array}$ & \\
\hline
\end{tabular}

坐刘の物理的性所

融点, 溶解時間, 硬度測定法および測定条件は，すべ
て前報3) と同一とした，測定結果を Table 2 に示 す.

Table 2. Melting Point, Dissolution Time and Hardness of Suppositories (Mean of five determinations)

\begin{tabular}{cccc}
\hline $\begin{array}{c}\text { Formula } \\
\text { Number }\end{array}$ & $\begin{array}{c}\text { Melting } \\
\text { Point (0) }\end{array}$ & $\begin{array}{c}\text { Dissolution } \\
\text { Time (min) }\end{array}$ & $\begin{array}{c}\text { Hardness } \\
(\mathrm{kg})\end{array}$ \\
\hline 1 & 25.2 & 2.8 & 5.2 \\
2 & 25.3 & 2.3 & 5.1 \\
3 & 26.0 & 3.0 & 4.8 \\
4 & 26.3 & 3.1 & 4.9 \\
5 & 25.8 & 2.5 & 4.7 \\
6 & 26.0 & 2.4 & 4.9 \\
7 & 26.0 & 2.6 & 5.0 \\
\hline
\end{tabular}

\section{吸収試験およびジゴキシン血中湌度測定}

坐剂の吸収試験は，実験動物として白色雄性家鬼を用 い3 羽を 1 群とし, 家鬼体重 $\mathrm{kg}$ 当りジゴキシン $0.3 \mathrm{mg}$ 飞 なるように投与した，その他動物の実験方法は前報》と 同一条件で実施した．採血は坐剤投与後 30 分, $1.5,4.5$, 7 拉よび 9 時間に行った。採血後遠心分離によって得ら れた血漿を, ジゴキシン血中濃度測定用の試料とした. ジゴキシン家鬼血中濃度は，1 抗体法によるラジオイム ノアッちイ (the Radiochemical Centre, 科研化学) 飞
より測定した.

\section{䊅 果 \\ ジコキシン血中勤悠}

Fig. 1 は基準坐剂として投与した Iの血中濃度一時間 曲線である。最高血中濃度は投与後30分付近にあり,1.6 - $3.7 \mathrm{ng} / \mathrm{ml}$ で，平均值は $2.8 \mathrm{ng} / \mathrm{ml}$ であった． 9 時間 後の血中濃度は $0.6-0.4 \mathrm{ng} / \mathrm{ml}$ の範用にあり, 平均値は $0.5 \mathrm{ng} / \mathrm{ml}$ であった。 


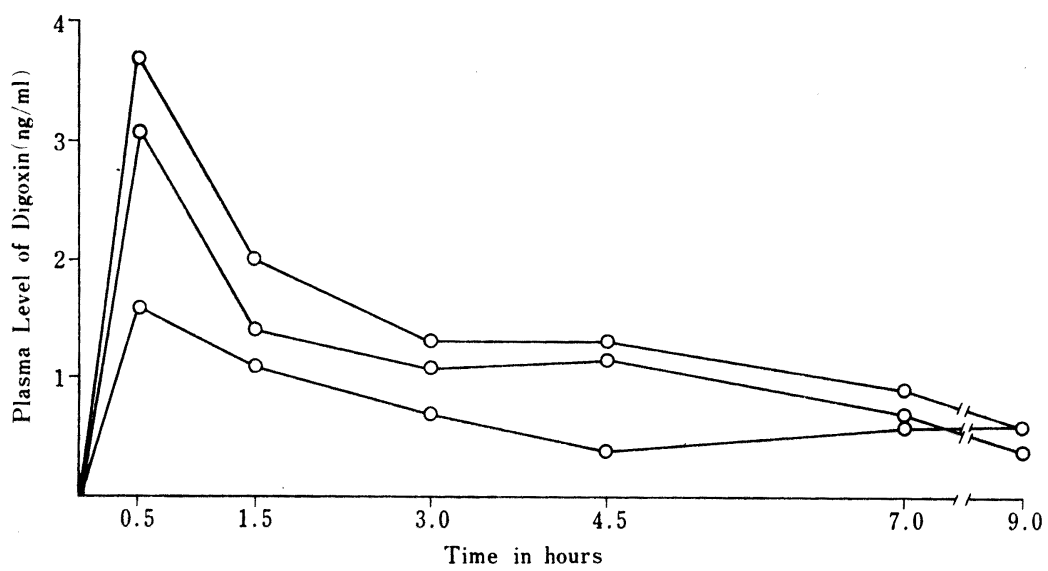

Fig. 1. Plasma Levels of Digoxin after Rectal Administration with Digoxin Suppository Containing $5 \%$ of Polysorbate 60

Fig. 2 は SFAE-11 を 1,2 および $5 \%$ 添加したジゴ キシン坐剤（以下 $\mathrm{II}, \mathbb{I I}, \mathrm{N}$ とする）の血中濃度一時間 曲線である. 群平均血中濃度の最高値はいずれる投与後
30 分付近にあり，それぞれ $2.2,1.3,2.6 \mathrm{ng} / \mathrm{ml}$ であっ た. 9 時間後の血中濃度は, $0.4,0.6$ および $0.6 \mathrm{ng} / \mathrm{m} 1$ と低下した。

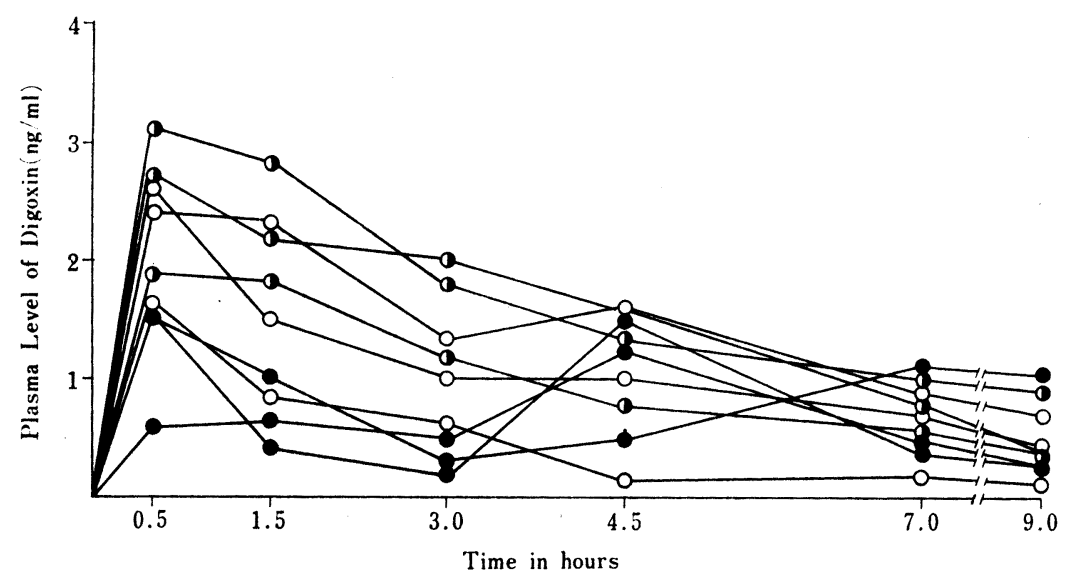

Fig. 2. Plasma Levels of Digoxin after Rectal Administration with Digoxin Suppository Containing SFAE-11 $(\bigcirc 1 \%, \bigcirc 2 \%, \bigcirc 5 \%)$

Fig. 3 はSFAE-15を 1, 2 および $5 \%$ 添加したジゴキ シン坐剤 (以下 $\mathrm{V}, \mathrm{U}, \mathrm{UI}$ とする) の血中濃度一時間 曲線である. 群平均血中濃度は最も高い值を示し, 投与 後30分の值は.4.1, 5.6 および $6.2 \mathrm{ng} / \mathrm{ml}$ であり, 9 時

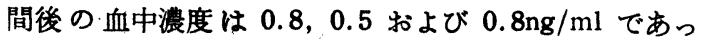
た.

Table 3 は, Table 1 に示した 7 種 のジゴキシン坐 剤の平均血中濃度および投与後 9 時間までの血中襄度一 時間曲線下の面積比（以下 AUC とする）を示す。

\section{考察}

先の実験で polysorbate 60 の 1,5 および $10 \%$ を添 加したジゴキシン坐剤の投与では, 基準坐剤のおよそ3, 6,9 倍の AUC が得られ, また投与後 30 分に扑ける最 高血中濃度も添加量の增加とともに上昇した ${ }^{3)}$. SFAE15のHLB值は約15と polysorbateとほぼ同じであり，実 験前の段階では polysorbafe 60 飞類似した吸収パター ンが予想されたので，さらに安定した血中動熊を期待し 


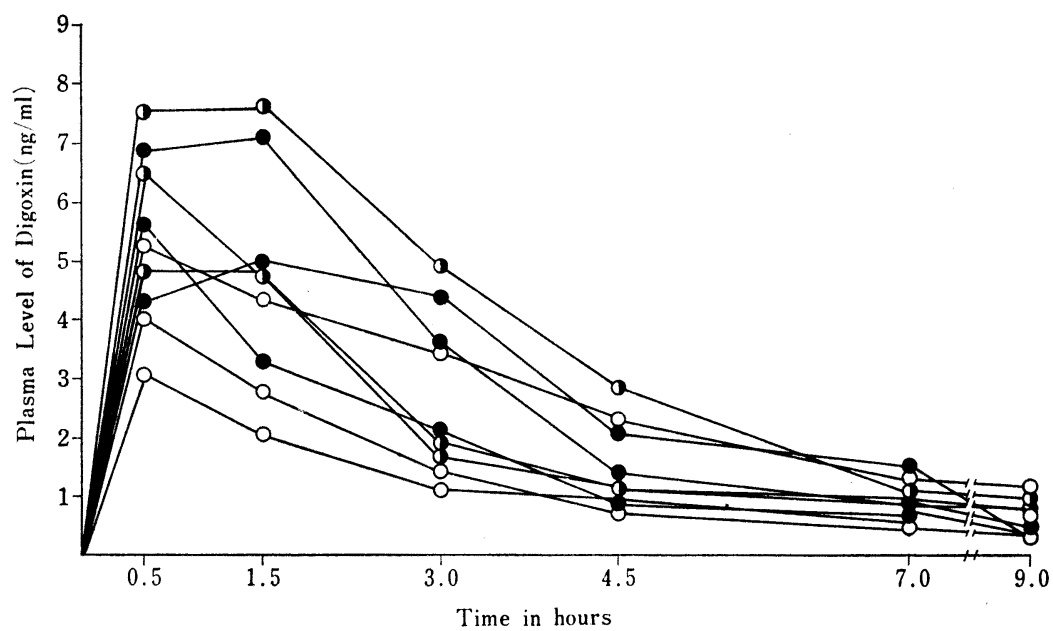

Fig. 3. Plasma Levels of Digoxin after Rectal Administration with Digoxin Suppository Containing SFAE-15 (O1\%, $2 \%, \bigcirc 5 \%)$

Table 3. Mean Values of Plasma Concentration $(\mathrm{ng} / \mathrm{ml}$ ) after Administration of $0.3 \mathrm{mg} / \mathrm{kg}$ of Digoxin to Three Rabbits and Relative Areas under Concentration-Time Curve

\begin{tabular}{|c|c|c|c|c|c|c|c|c|}
\hline \multirow[t]{2}{*}{$\begin{array}{l}\text { Formula } \\
\text { number }\end{array}$} & \multicolumn{7}{|c|}{$\begin{array}{c}\text { Plasma digoxin concentration } \\
( \pm \text { S.E.M.) }\end{array}$} & \multirow{2}{*}{$\begin{array}{l}\text { Relative area } \\
\text { under concen- } \\
\text { tration-time } \\
\text { curve }\end{array}$} \\
\hline & 0 & 0.5 & 1.5 & 3.0 & 4.5 & 7.0 & 9.0 & \\
\hline 1 & 0 & $\begin{array}{l}2.8 \\
(0.6)\end{array}$ & $\begin{array}{l}1.5 \\
(0.2)\end{array}$ & $\begin{array}{l}1.0 \\
(0.2)\end{array}$ & $\begin{array}{l}1.0 \\
(0.3)\end{array}$ & $\begin{array}{c}0.7 \\
(0.1)\end{array}$ & $\begin{array}{l}0.5 \\
(0.1)\end{array}$ & 1 \\
\hline 2 & 0 & $\begin{array}{c}2.2 \\
(0.3)\end{array}$ & $\begin{array}{l}1.6 \\
(0.4)\end{array}$ & $\begin{array}{l}1.0 \\
(0.2)\end{array}$ & $\begin{array}{l}0.9 \\
(0.4)\end{array}$ & $\begin{array}{c}0.6 \\
(0.2)\end{array}$ & $\begin{array}{l}0.4 \\
(0.2)\end{array}$ & 0.67 \\
\hline 3 & 0 & $\begin{array}{l}1.3 \\
(0.3)\end{array}$ & $\begin{array}{c}0.7 \\
(0.2)\end{array}$ & $\begin{array}{l}0.3 \\
(0.1)\end{array}$ & $\left(\begin{array}{l}1 \cdot 1 \\
(0.3)\end{array}\right.$ & $\begin{array}{c}0.7 \\
(0.2)\end{array}$ & $\begin{array}{c}0.6 \\
(0.3)\end{array}$ & 0.87 \\
\hline 4 & 0 & $\begin{array}{c}2.6 \\
(0.4)\end{array}$ & $\begin{array}{c}2.3 \\
(0.3)\end{array}$ & $\begin{array}{l}1.7 \\
(0.2)\end{array}$ & $\begin{array}{l}1.2 \\
(0.1)\end{array}$ & $\begin{array}{c}0.8 \\
(0.2)\end{array}$ & $\begin{array}{l}0.6 \\
(0.2)\end{array}$ & 1.23 \\
\hline 5 & 0 & $\begin{array}{c}4.1 \\
(0.6)\end{array}$ & $\begin{array}{l}3.1 \\
(0.7)\end{array}$ & $\begin{array}{l}2.0 \\
(0.7)\end{array}$ & $\begin{array}{l}1.4 \\
(0.5)\end{array}$ & $\begin{array}{c}0.8 \\
(0.2)\end{array}$ & $\begin{array}{l}0.8 \\
(0.2)\end{array}$ & 1.52 \\
\hline 6 & 0 & $\begin{array}{l}5.6 \\
(0.8)\end{array}$ & $\begin{array}{c}5.1 \\
(1.1)\end{array}$ & $\begin{array}{c}3.1 \\
(0.7)\end{array}$ & $\begin{array}{l}1.5 \\
(0.4)\end{array}$ & $\begin{array}{l}1.0 \\
(0.2)\end{array}$ & $\begin{array}{c}0.5 \\
(0.1)\end{array}$ & 2.14 \\
\hline 7 & 0 & $\begin{array}{c}6.2 \\
(0.8)\end{array}$ & $\begin{array}{c}5.8 \\
(0.9)\end{array}$ & $\begin{array}{c}2.9 \\
(1.0)\end{array}$ & $\begin{array}{c}1.7 \\
(0.6)\end{array}$ & $\begin{array}{l}1.0 \\
(0.1)\end{array}$ & $\begin{array}{c}0.8 \\
(0.1)\end{array}$ & 2.33 \\
\hline
\end{tabular}

S.E.M.: standard error of the mean

て SFAE-11 を SFAE-15 と同一濃度で添加した坐剂 で並行して実験を行った，基阂に対する界面活性斉の添 加量は, 直腸に投与された薬物の血中動態に大さく影響 することから, 先の実験結果を検討し界面活性剤のおよ

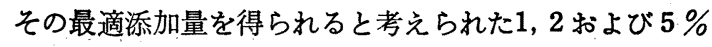
を選んだ.

SFAE 添加による持続効果を, 投与後 1.5 時間のジゴ キシン血中濃度/投与後 0.5 時間の血中濃度を指標とし て比較すると, 坐剂 I では 0.54, II, III, N, V, V, および 【Iではそれぞれ $0.70,0.55,0.89,0.77,0.91$ および 0.94 であった。これらの值から SFAE の添加が
投与後 1.5 時間付近までは坐剂 Iよりる持続作用を持つ と考えられる。また坐昘投与後 9 時間までの AUCで比 較すると, SFAE-11 の添加では $\mathrm{N}$ でのみ基準坐剤をこ える AUC が得られた. V, V, UI の AUC は 1.52, $2.14,2.33$ であり, すべて基準坐剤 $I$ をこえる值が 得 られた. SFAE-15添加のジゴキシン坐剤 V, および UI の血中ジゴキシン濃度間には有意差は認められず（p） 0.05）約 $2 \%$ 添加量として 適当であることが判明し た.

さらに持続作用を詳細に検討するため, AUC を 4.5 時間までと 4.5 時間以降 9 時間までに区切って坐剂 I と 


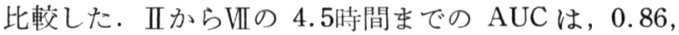
$0.50,1.29,1.64,2.50,2.71$ と $0-9$ 時間のAUC に 近い值であるが， 4.5 時間以降は，0.75，1.01，1.02， $1.13 ， 1.25 ， 1.38$ と基準とした I の值にほぼ等しいか, わす゚かに大きい值であった。

$$
\text { ま と め }
$$

SFAE-11を 1，2 拈よび $5 \%$ 添加した坐剂では， $5 \%$ 添加した坐剂でのみ基準坐剂 I をこえる AUC が得られ た.SFAE-15を 1，2および $5 \%$ 添加した坐剤では， すべて基準坐剤Iをこえる AUC が得られ，2\%および $5 \%$ 添加により得られた各血中濃度間には有意差は認め られなかった（p>0.05）. 投与後 1.5 時間の血中ジゴキ シン濃度/投与後 0.5 時間の血中ジゴキシン濃度, およ
び AUC を指標として評価した SFAE 添加ジゴキシン坐 剂の持続作用は， $\mathrm{N}, \mathrm{V}, \mathrm{V}, \mathrm{VI}$ 飞認められ，基準坐 剂 I と比較した作用持続時間は㧤よそ 4.5 時間と考えら れる。

$$
\text { 交献 }
$$

1）掛見喜一郎, 有田隆一, 瀬崎 巵, 杉本 功: 薬 剂学, 25, 19 (1967).

2) 竹中英雄, 伊藤 元, 栢野正則, 大橋 芳 : 薬剂 学, 25, 285 (1967).

3）米沢健三, 山口 勇, 板橋芳夫, 伊庭 茂, 金久 保好男, 中村 護: 薬剂学 38, 174 (1978).

4）食品添加物公定書注解編集委員会編：第三版食品 添加物公定書注解，金原出版，1974.

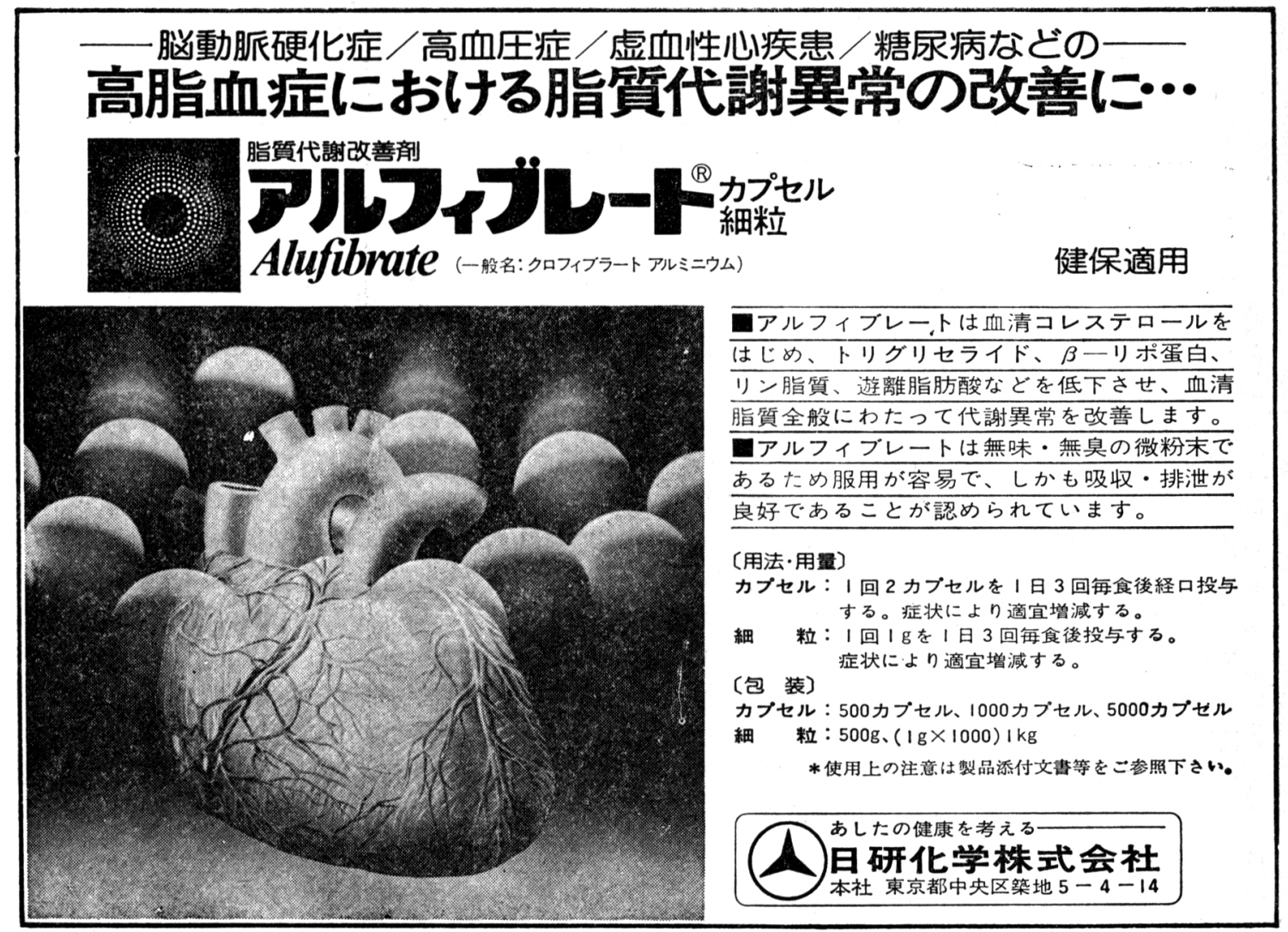

